\title{
Quantitation of angiogenesis in vitro induced by VEGF-A and FGF-2 in two different human endothelial cultures - an all-in-one assay
}

\author{
Mahtab Bahramsoltani ${ }^{\mathrm{a}, *}$, Ward De Spiegelaere ${ }^{\mathrm{b}}$, Pawel Janczyk ${ }^{\mathrm{c}}$, Bernhard Hiebl ${ }^{\mathrm{d}}$, \\ Pieter Cornillie $^{\mathrm{b}}$ and Johanna Plendl ${ }^{\mathrm{c}}$ \\ anstitute of Veterinary Anatomy, Faculty of Veterinary Medicine, University of Leipzig, Leipzig, Germany \\ ${ }^{\mathrm{b}}$ Department of Morphology, Faculty of Veterinary Medicine, Ghent University, Ghent, Belgium \\ ${ }^{\mathrm{c}}$ Institute of Veterinary Anatomy, Department of Veterinary Medicine, Freie Universität Berlin, \\ Berlin, Germany \\ ${ }^{\mathrm{d}}$ Berlin-Brandenburg Centre for Regenerative Therapies, Institute of Polymer Research, GKSS \\ Research Centre Geesthacht, Teltow, Germany
}

\begin{abstract}
Angiogenic therapy is considered to be a promising tool for treatment of ischemic diseases. Many in vivo and in vitro assays have been developed to identify potential proangiogenic drugs and to investigate their mode of action. However, until now no validated system exists that would allow quantitation of angiogenesis in vitro in only one assay. Here, a previously established all-in-one in vitro assay based on staging of the angiogenic cascade was validated by quantitation of the effects of the known proangiogenic factors VEGF-A and FGF-2. Both growth factors were applied separately or in combination to human endothelial cell cultures derived from the heart and the foreskin, and angiogenesis was quantitated over 30 days of culture. Additionally, gene expression of VEGFR-1, VEGFR-2 and FGFR-1 at 3, 10, 20 or 40 days of cultivation was quantitated by RT-qPCR. In both cultures, VEGF-A as well as FGF-2 induced a run through all defined stages of angiogenesis in vitro. Application of VEGF-A only led to formation of irregular globular endothelial structures, while FGF-2 resulted in development of regular capillary-like structures. Quantitation of the angiogenic effects of VEGF-A and transcripts of VEGFR-1 and VEGFR-2 showed that a high VEGFR-1/VEGFR-2 ratio evoked deceleration of angiogenesis.
\end{abstract}

Keywords: Angiogenesis, quantitative in vitro assay, VEGF-A, FGF-2

\section{Introduction}

Angiogenesis, i.e. the sprouting of vessels from pre-existing ones, and its inhibition, antiangiogenesis, are involved in a variety of diseases. Both, the therapeutic use of antiangiogenic drugs for treatment of cancer as well as application of proangiogenic substances to improve perfusion of ischemic tissues gain in

\footnotetext{
${ }^{*}$ Corresponding author: Dr. Mahtab Bahramsoltani, Institute of Veterinary Anatomy, Faculty of Veterinary Medicine, University of Leipzig, An den Tierkliniken 43, 04103 Leipzig, Germany. Tel.: +49 341 9738034; Fax: +49 341 9738039; E-mail: bahramsoltani@vetmed.uni-leipzig.de.
} 
importance in modern medicine [10,43]. To date numerous pro- and antiangiogenic substances have been identified or developed and their molecular effects on endothelial cells have been studied exhaustively [32]. These factors interfere with the steps of the angiogenic cascade, i.e. degradation of the basal lamina, migration and proliferation of endothelial cells, lumenisation of new sprouts and endothelial secretion of basal lamina components to stabilise the newly formed vessels $[2,8]$. Since we and others have shown that successful manipulation of angiogenesis or antiangiogenesis depends on drugs, interfering with all steps of angiogenesis, it is indispensable to determine precisely the steps in which pro- or antiangiogenic substances influence the angiogenic cascade [4, 11, 23, 42]. These investigations on angiogenesis and antiangiogenesis are primarily performed in vitro. Therefore, different in vitro assays of angiogenesis are available, and all of them are based on only one specific, single step of the angiogenic cascade [2, 5]. However, the extrapolation of observed effects within in vivo experiments or even in clinical trials frequently lead to disappointing results in preclinical and clinical application [20].

Supposing that this might be due to the lack of comparability of the different angiogenesis assays, this study was performed to verify the effects of known proangiogenic factors with a previously established method, that allows investigation and quantitation of all steps of the angiogenic cascade in one single assay $[3,4]$, applying two different human endothelial cell cultures.

Therefore, Vascular Endothelial Growth Factor A (VEGF-A) and Fibroblast Growth Factor 2 (FGF-2) were chosen, as their effects have been extensively investigated in vivo as well as in vitro and they are considered to be the most potent stimulators of angiogenesis $[16,33]$.

The VEGF family includes several proteins, i.e. VEGF-A, VEGF-B, VEGF-C, VEGF-D, VEGF-E and Placenta Growth Factor (PIGF). Within this family VEGF-A is the most potent stimulator of angiogenesis [21]. Seven proangiogenic isoforms of VEGF-A (VEGF-A121, VEGF-A145, VEGF-A162, VEGF-A165, VEGF-A183, VEGF-A189, VEGF-A206) are known to arise from alternative splicing. These variants all display the same biological activity, but they differ in their capacity to bind to heparin and the extracellular matrix. VEGF-A165 is the predominant splice variant, and it is usually designated as VEGF-A. VEGF-A acts via two different blood vessel endothelial receptors, i.e. VEGFR-1 (fms-like tyrosine kinase) and VEGFR-2 (fetal liver kinase 1/kinase domain region), while VEGFR-3 is largely restricted to lymphatic endothelial cells $[21,24,25,30]$.

FGF-2 (also known as basic FGF) is a member of a large family of structurally homologous, functionally distinct small polypeptides, which are potent regulators of cell growth and differentiation in a variety of cell types [33]. Only FGF-1 and FGF-2 are expressed at high levels in the adult organism. While expression of FGF-1 is primarily constricted to the central nervous system, FGF-2 is expressed throughout all tissues and cells including endothelial cells [36]. FGF-2 exerts its effects by interaction with both cell surface receptor tyrosine kinases (FGFR1-4) and extracellular and cell-surface-bound heparan sulphate proteoglycans (HSPGs). FGFRs mediate the effects of FGF-2 on cells, whereas the more general role of HSPGs is the modulation of FGF-2 binding to its receptors. FGFR1 and FGFR2 are expressed on endothelial cells, but FGFR1 is more abundant [39]. The cellular effect of FGF-2 via FGFR-1 consists in the release of urinary plasminogen activator and collagenase in endothelial cells, enabling their migration. Additionally, FGF-2 acts as a chemoattractant for endothelial cells also effecting their migration [1].

The aim of this study was to investigate, whether the previously established all-in-one in vitro angiogenesis assay could be used to confirm and quantitate the proangiogenic effects of VEGF-A and FGF-2 in two different human microvascular endothelial cell cultures in the course of method validation. Additionally, for evaluation of the effects of VEGF-A and FGF-2, the gene expression of their blood vessel endothelial cell specific receptors, i.e. VEGFR-1, VEGFR-2 and FGFR-1, was measured during cultivation in both cell types. 


\section{Materials and methods}

\subsection{Human endothelial cells and media}

Human microvascular endothelial cells derived either from the heart muscle of a 54 year old female (HCMEC), or from the neonatal foreskin (HDMEC) were purchased from Lonza Biosciences (Verviers, Belgium; original catalogue cell culture names: HMVEC-C Cardiac MV Endo Cells and HMVECdBINeo, respectively).

A basic medium (BM) serving as negative control was constituted by using the growth medium provided by the distributors (EBM-2/EGM-2 MV, Lonza Bioscience, Verviers, Belgium) without growth factors and with only $2 \%$ of the provided serum. This medium composition turned out to retain cell survival but did not result in any angiogenic response of cells.

For positive controls the provided growth medium was used as suggested by the distributors (positive medium, PM). This medium consisted of a mixture of several growth factors including Epidermal Growth Factor (EGF), Insulin-like Growth Factor 1 (IGF-1), hydrocortisone and some less specified components such as Bovine Brain Extract and Fetal Bovine Serum in addition to VEGF-A and FGF-2. Preliminary works in our laboratory showed that this medium stimulates endothelial cells to run through all phases of the angiogenic cascade in vitro within 30-40 days.

\subsection{Growth factors}

The growth factors VEGF-A (human, recombinant antigen; Strathmann Biotec, Hamburg, Germany) and/or FGF-2 (human, recombinant antigen; Strathmann Biotec, Hamburg, Germany) were added to the basic medium. Concentrations of VEGF-A and FGF-2 were determined according to Cavallaro et al. [13], who used these factors at a concentration of $10 \mathrm{ng} / \mathrm{ml}$. In a pilot study performed in our laboratory, the effects of both growth factors were tested at concentrations of $5 \mathrm{ng} / \mathrm{ml}, 10 \mathrm{ng} / \mathrm{ml}$ and $20 \mathrm{ng} / \mathrm{ml}$. Results showed that no angiogenic effect of VEGF-A or FGF-2 could be observed at a concentration of $5 \mathrm{ng} / \mathrm{ml}$. However, when concentrations of 10 or $20 \mathrm{ng} / \mathrm{ml}$ were used, similar angiogenic effects were recorded (unpublished data). Therefore, the concentration of $10 \mathrm{ng} / \mathrm{ml}$ of each growth factor was chosen for this study.

\subsection{In vitro angiogenesis assay}

Endothelial cells seeded in gelatine-coated 24-well plates (Iwaki, Tokyo, Japan) at a concentration of $4.1-4.5 \times 10^{4}$ cells per well were cultivated for 30 days.

Phase-contrast microscopy was carried out daily applying an inverted microscope (Axiovert 25; Zeiss, Jena, Germany). Digital pictures were taken with a video camera (Inteq 000610; Inteq, Berlin, Germany) and the image editing system Axiovision (Version 3.0; Zeiss, Jena, Germany).

Quantitation of angiogenesis was carried out by the previously established method [3, 4]. In brief, cells were incubated in the proangiogenic medium and the changes of endothelial cell morphology observed in the course of the angiogenic cascade in vitro were classified as six defined stages (Table 1). On the first day of investigation, visual fields were chosen randomly and defined per coordinates. Thenceforward, these visual fields were photographed every second day (investigation days). The obtained cell images were assigned to the respective stage of angiogenesis. For each visual field the time-dependent course of angiogenesis was investigated by calculating the sum of assigned stages of angiogenesis in vitro during 
Table 1

Definition of stages of angiogenesis in vitro and description of cell morphology within the different stages

\begin{tabular}{|c|c|}
\hline Stage no. & Morphology of endothelial cells \\
\hline Stage 1 & $\begin{array}{l}\text { Confluent monolayer } \\
\text { Polygonal shaped cells }\end{array}$ \\
\hline Stage 2 & $\begin{array}{l}\text { Endothelial sprouting, late phase } \\
>50 \% \text { elongated shaped cells }\end{array}$ \\
\hline Stage 3 & $\begin{array}{l}\text { Linear side by side arrangement, late phase } \\
>50 \% \text { linearly arranged cells }\end{array}$ \\
\hline Stage 4 & $\begin{array}{l}\text { Networking } \\
\text { Network of linearly arranged cells }\end{array}$ \\
\hline Stage 5 & $\begin{array}{l}\text { Three-dimensional organisation, early phase } \\
\text { Appearance of capillary-like structures (linear structures of endothelial cells with } \\
\text { a diameter of more than } 28 \mu \mathrm{m} \text {; for these structures an internal lumen was shown } \\
\text { by electron microscopy) }\end{array}$ \\
\hline Stage 6 & $\begin{array}{l}\text { Three-dimensional organisation, late phase } \\
\text { All linearly arranged cells form capillary-like structures; dissolution of the cell layer } \\
\text { on the bottom }\end{array}$ \\
\hline
\end{tabular}

all investigation days. Extensive validation of this method showed that representative quantitation can be carried out in 4 wells and 4 visual fields per well.

Quantitation of angiogenesis induced by VEGF-A and FGF-2 was carried out as follows: A negative control was cultivated in BM, and three experiment groups were cultivated in BM supplemented with VEGF-A, FGF-2 as well as VEGF-A and FGF-2, respectively. Cells were also incubated in PM as positive controls; their run through the stages of angiogenesis provided a standard curve, characteristic for each cell culture. The documentation of the visual fields was performed over 30 days, every second day (15 investigation days) as described above. Two visual fields were chosen from the border area and 2 visual fields from the centre of the culture well. For each visual field, the sum of assigned stages at the 15 investigation days $(S)$ was calculated. The proangiogenic effects of VEGF-A, FGF-2 or VEGF-A and FGF-2 were determined by calculating the ratio of the arithmetic mean of the sums of the 16 visual fields

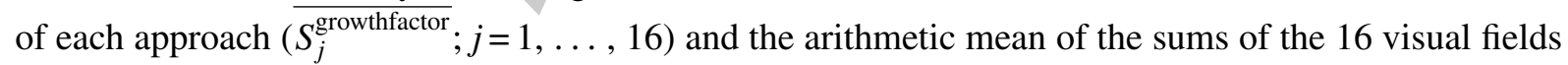
derived from the cells incubated in $\mathrm{PM}\left(\overline{S_{j}^{\mathrm{PM}}} ; j=1, \ldots, 16\right)$.

Analysis of variance (ANOVA) and a post-hoc Tukey-HSD test was performed on the obtained data using the STATISTICA Vers. 6.0 software (StatSoft, Tulsa, OK, USA) to determine the differences between treatments $(p<0.05)$.

\subsection{Quantitative analysis of VEGFR-1, VEGFR-2 and FGFR-1 transcripts by RT-qPCR}

Cells were harvested on the 3rd, 10th, 20th or 40th day of cultivation. Total RNA was isolated from the cells using the Invisorb Spin Cell RNA Mini Kit (Invitek, Berlin, Germany). The isolated RNA was reverse transcribed with the First Strand cDNA Synthesis Kit (K1612, Fermenta, St. Leon-Rot, Germany). Quantitative PCR was performed with the Rotor Gene 6000 (Corbett, Wasserburg, Germany) using Maxima ${ }^{\mathrm{TM}}$ SYBR Green/Fluorescein qPCR Master Mix (2X) (Fermentas, St. Leon-Rot, Germany). 
All samples were run in duplicate and each run included a serial dilution of a cDNA mix of all the samples to obtain a standard curve for each gene. Gene specific primers (Table 2) were either selected from literature or designed using RTprimerDB [26]. Analysis of gene expression with quantitative PCR (qPCR) requires the knowledge of the amount of starting material in each sample. This estimation is best performed through normalisation with multiple reference genes [40]. In this survey, 10 reference genes were initially tested between the different samples as to identify the most stable reference genes (Table 2), which could then be used for the further normalisation. Using the GeNorm software [40], 4 reference genes were identified for the calculation of the sample specific normalisation factors (from most stable to less stable: GAPDH, UBC, TBP and HPRT). Normalized relative quantities of the mRNA coding for VEGFR-1, VEGFR-2 and FGFR-1 were calculated using REST [31] and qBase [22] with

Table 2

List of primers, used for RT-qPCR. Genes of interest: FGFR1, VEGFR-1 and VEGFR-2; reference genes: Actin, beta (ACTB), beta-2-microglobulin (B2M), glyceraldehyde-3-phosphate dehydrogenase (GAPDH), hydroxymethylbilane synthase (HMBS), hypoxanthine phosphoribosyltransferase 1 (HPRT1), ribosomal protein L13 (RPL13), succinate dehydrogenase complex, subunit A (SDHA), tyrosine 3-monooxygenase/tryptophan 5-monooxygenas (YWHAZ), TATA box binding protein (TBP), ubiquitin C (UBC)

\begin{tabular}{|c|c|c|c|c|c|}
\hline Gene & Orientation & Primer sequence $\left(5^{\prime}-3^{\prime}\right)$ & $\begin{array}{l}\text { Amplicon } \\
\text { length } \\
\text { (bp) }\end{array}$ & $\begin{array}{c}\text { Annealing } \\
\text { temperature } \\
\left({ }^{\circ} \mathrm{C}\right)\end{array}$ & $\begin{array}{l}\text { GenBank accession } \\
\text { no. or reference }\end{array}$ \\
\hline VEGFR-1 & $\begin{array}{l}\text { Forward } \\
\text { Reverse }\end{array}$ & $\begin{array}{l}\text { GACCTGGAGTTACCCTGATGAAA } \\
\text { GGCATGGGAATTGCTTTGG }\end{array}$ & 76 & 60 & NM_002019 \\
\hline VEGFR-2 & $\begin{array}{l}\text { Forward } \\
\text { Reverse }\end{array}$ & $\begin{array}{l}\text { CACCACTCAAACGCTGACATGTA } \\
\text { GCTCGTTGGCGCACTCTT }\end{array}$ & 95 & 60 & Sussman et al. [35] \\
\hline FGFR1 & $\begin{array}{l}\text { Forward } \\
\text { Reverse }\end{array}$ & $\begin{array}{l}\text { CCTCTATGTGGGCATGGTTT } \\
\text { TACAGGAAGGACGATCTGGG }\end{array}$ & 131 & 60 & NM_015850 \\
\hline ACTB & $\begin{array}{l}\text { Forward } \\
\text { Reverse }\end{array}$ & $\begin{array}{l}\text { CCTGGCACCCAGCACAAT } \\
\text { GGGCCGGACTCGTCATACT }\end{array}$ & 145 & 60 & Sussman et al. [35] \\
\hline B2M & $\begin{array}{l}\text { Forward } \\
\text { Reverse }\end{array}$ & $\begin{array}{l}\text { ATGAGTATGCCTGCCGTGTG } \\
\text { GGCATCTTCAAACCTCCATG }\end{array}$ & 101 & 60 & Murphy et al. [28] \\
\hline GAPDH & $\begin{array}{l}\text { Forward } \\
\text { Reverse }\end{array}$ & $\begin{array}{l}\text { GCAAATTCCATGGCACCGT } \\
\text { GCCCCACTTGATTTTGGAGG }\end{array}$ & 104 & 60 & NM_002046 \\
\hline HMBS & $\begin{array}{l}\text { Forward } \\
\text { Reverse }\end{array}$ & $\begin{array}{l}\text { ACCAAGGAGCTTGAACATGC } \\
\text { GAAAGACAACAGCATCATGAG }\end{array}$ & 145 & 60 & Steckelbroeck et al. [34] \\
\hline HPRT1 & $\begin{array}{l}\text { Forward } \\
\text { Reverse }\end{array}$ & $\begin{array}{l}\text { AATTATGGACAGGACTGAACGTCTTGCT } \\
\text { TCCAGCAGGTCAGCAAAGAATTTATAGC }\end{array}$ & 114 & 60 & Baudry et al. [6] \\
\hline RPL13 & $\begin{array}{l}\text { Forward } \\
\text { Reverse }\end{array}$ & $\begin{array}{l}\text { CCCGTCCGGAACGTCTATAA } \\
\text { CTAGCGAAGGCTTTGAAATTCTTC }\end{array}$ & 77 & 60 & NM_000977 \\
\hline SDHA & $\begin{array}{l}\text { Forward } \\
\text { Reverse }\end{array}$ & $\begin{array}{l}\text { TGGGAACAAGAGGGCATCTG } \\
\text { CCACCACTGCATCAAATTCATG }\end{array}$ & 86 & 60 & Vandesompele et al. [40] \\
\hline YWHAZ & $\begin{array}{l}\text { Forward } \\
\text { Reverse }\end{array}$ & $\begin{array}{l}\text { ACTTTTGGTACATTGTGGCTTCAA } \\
\text { CCGCCAGGACAAACCAGTAT }\end{array}$ & 94 & 60 & Vandesompele et al. [40] \\
\hline TBP & $\begin{array}{l}\text { Forward } \\
\text { Reverse }\end{array}$ & $\begin{array}{l}\text { TGCACAGGAGCCAAGAGTGAA } \\
\text { CACATCACAGCTCCCCACCA }\end{array}$ & 133 & 60 & Dallol et al. [14] \\
\hline UBC & $\begin{array}{l}\text { Forward } \\
\text { Reverse }\end{array}$ & $\begin{array}{l}\text { ATTTGGGTCGCGGTTCTTG } \\
\text { TGCCTTGACATTCTCGATGGT }\end{array}$ & 132 & 60 & Vandesompele et al. [40] \\
\hline
\end{tabular}


the selected set of reference genes. The REST software analyses if gene-expression is significantly different between two sample groups using bootstrap randomisation [31]. The qBase software calculates normalised relative expression quantities which can then be further used for statistical analysis. The differences in the expression of the investigated genes $(p<0.05)$ were calculated by applying the $t$-test implemented in Sigmaplot (Systat, Erkrath, Germany).

\section{Results}

\subsection{Morphology of endothelial structures in course of angiogenesis in vitro induced by VEGF-A} and FGF-2

Cells incubated in BM showed a polygonal shape (stage 1) during the whole investigation period and served as negative controls. Cells incubated in PM were confirmed to serve as positive controls as they ran chronologically through the defined stages of angiogenesis in vitro during the investigation period of 30 days.
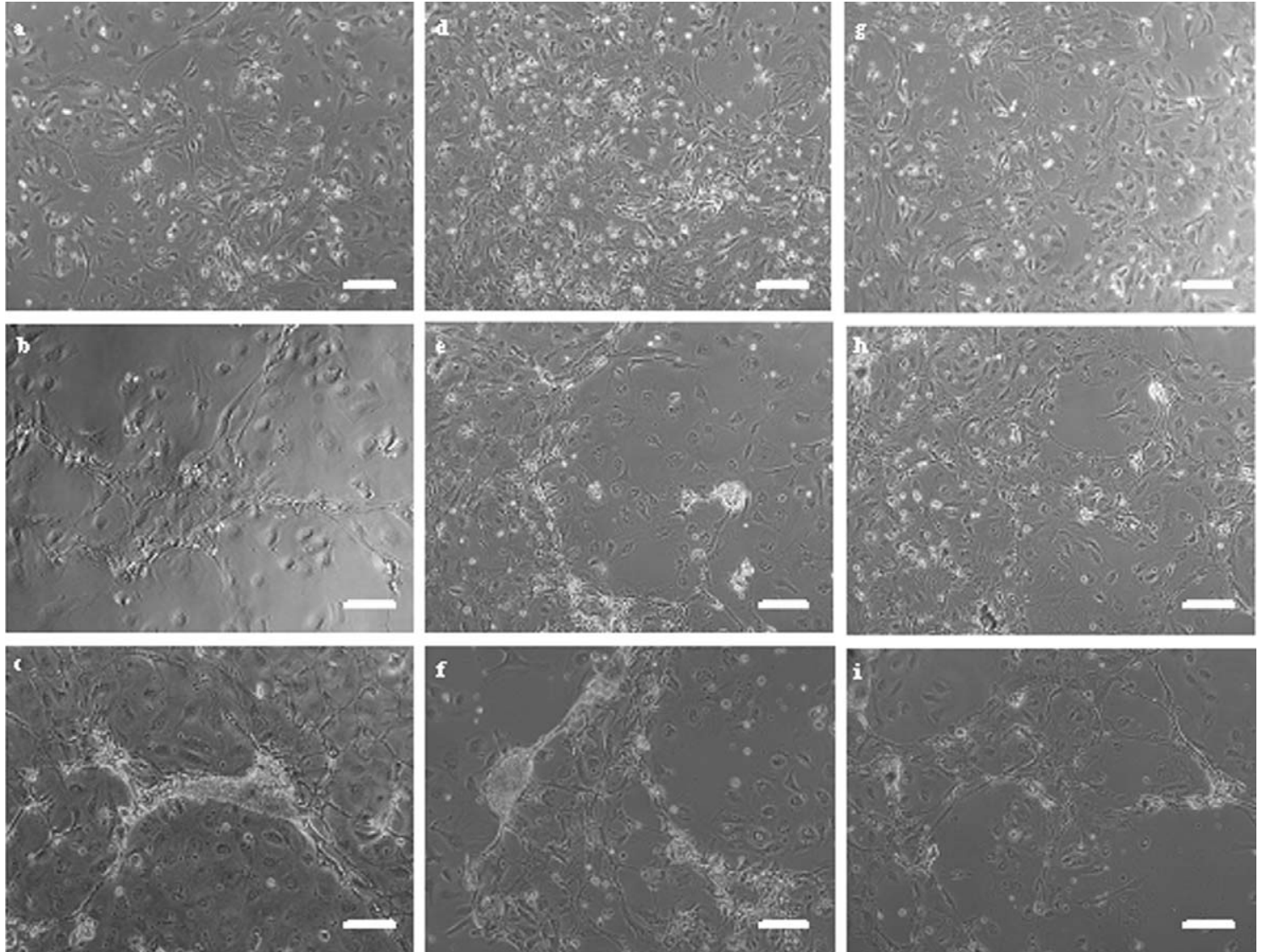

Fig. 1. Angiogenesis in vitro in human cardiac microvascular endothelial cells (HCMEC) cultivated in a basal medium supplemented with either FGF-2 (a-c) or VEGF-A (d-f), or both FGF-2 and VEGF-1 (h, i). Linear positioning of the cells in early stages 2-3 (a, d, g) was followed by forming of a network in stage $4(\mathrm{~b}, \mathrm{e}, \mathrm{h})$ and regular strand-like (c, i) or irregular globular structures (f) in stages 5-6. Bars: $50 \mu \mathrm{m}$. 
In HDMEC as well as in HCMEC effects on morphology were similar for each medium. The only difference consisted in the characteristic and in principle lower cell density of HCMEC displayed by an always discontinuous cell layer (Figs 1 and 2).

In all cultures, more than $50 \%$ of cells showed an elongated shape within 2-4 days (stage 2; Figs 1a, $\mathrm{d}, \mathrm{g}$ and $2 \mathrm{a}, \mathrm{d}, \mathrm{g}$ ). The following characteristic morphological changes of endothelial cells performing angiogenesis in vitro were observable in all specimens at the latest after 18 days, as stated in Table 1: linear arrangement of elongated cells (stage 3) and the formation of an endothelial network (stage 4; Figs 1b, e, h and 2b, e, h). Except for HCMEC cultured in PM, all cultures reached the final stages 5-6 within the investigation period of 30 days (Figs 1c, f, i and 2c, f, i). The threedimensional endothelial structures that appeared in stage 5-6 displayed continuously strand-like structures in HCMEC and HDMEC incubated in PM, FGF-2 or VEGF-A and FGF-2 (Figs 1c, i and 2c, i). Application of VEGF-A only resulted in the development of primarily irregular globular endothelial structures with variable diameters of approximately $30-50 \mu \mathrm{m}$. These globular structures were always attached to a fine network of very thin strand-like structures with diameters of at most $10 \mu \mathrm{m}$ (Figs $1 \mathrm{f}$ and 2f).
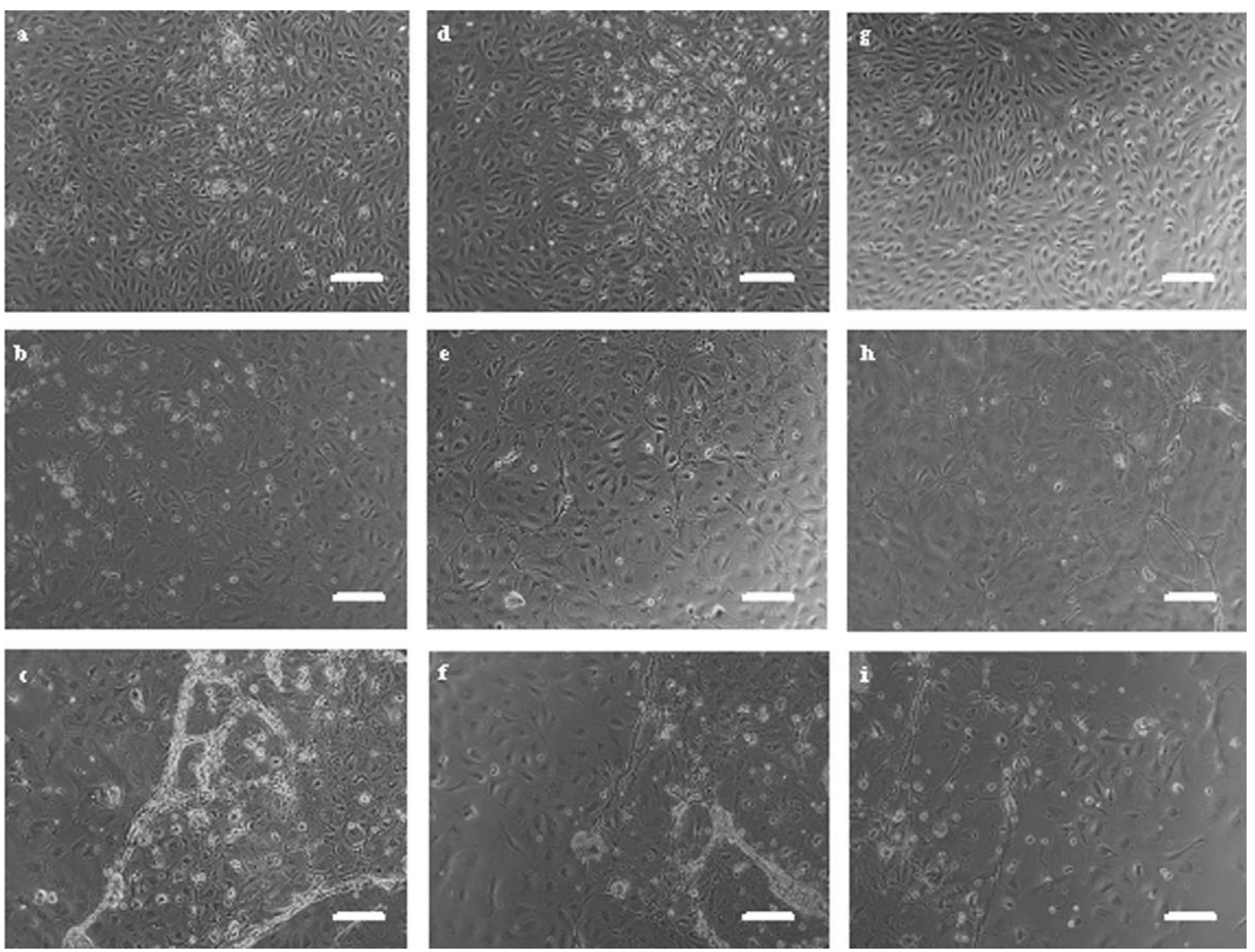

Fig. 2. Angiogenesis in vitro in human dermal microvascular endothelial cells (HDMEC) cultivated in a basal medium supplemented with either FGF-2 (a-c) or VEGF-A (d-f), or both FGF-2 and VEGF-A (h, i). Linear positioning of the cells in early stages 2-3 (a, d, g) was followed by forming of a network in stage $4(\mathrm{~b}, \mathrm{e}, \mathrm{h})$ and regular strand-like (c, i) or irregular globular structures (f) in stages 5-6. Bars: $50 \mu \mathrm{m}$. 


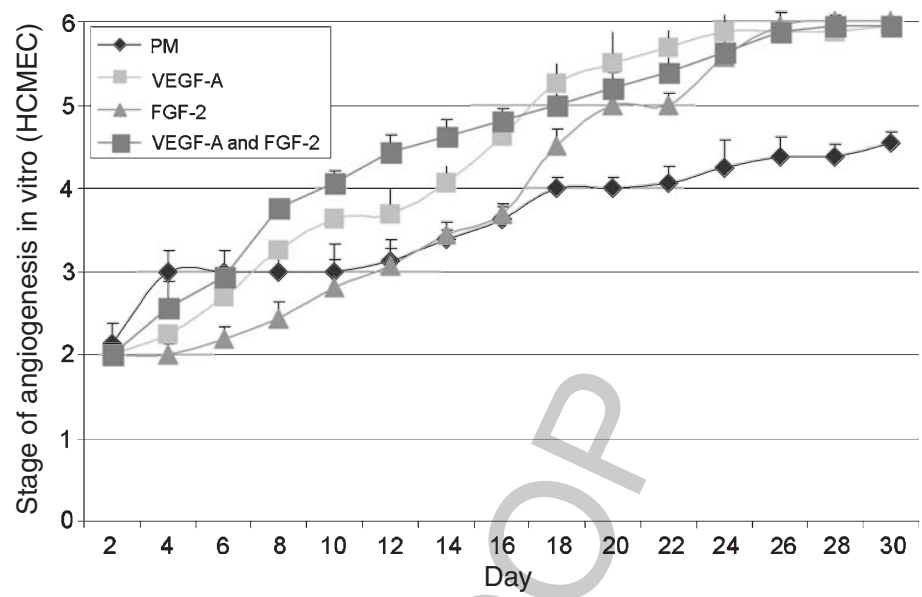

Fig. 3. Stages of angiogenesis in vitro of human cardiac microvascular endothelial cells (HCMEC) cultivated in a positive medium (PM), a basal medium supplemented with either FGF-2, or VEGF-A or with both FGF-2 and VEGF-A recorded for 4 visual fields in 4 wells per culture during 30 days, every second day. Mean values per culture with SD are presented. The stages of angiogenesis in vitro of cells incubated in PM differed to cells incubated in VEGF-A, FGF-2, VEGF-A and FGF-2 on day 4. The stages of angiogenesis in vitro of cells incubated in FGF-2 differed to the other specimens starting from day 6 , with exception for days 10-16 (not to PM). The stages of angiogenesis in vitro of cells incubated in PM differed to the other specimens starting from day 18 .

The time-dependent courses of the morphologically assigned stages of angiogenesis in HCMEC and HDMEC cultured in PM or BM in the presence of VEGF-A, FGF-2 or VEFG-A and FGF-2 are demonstrated in Figs 3 and 4.

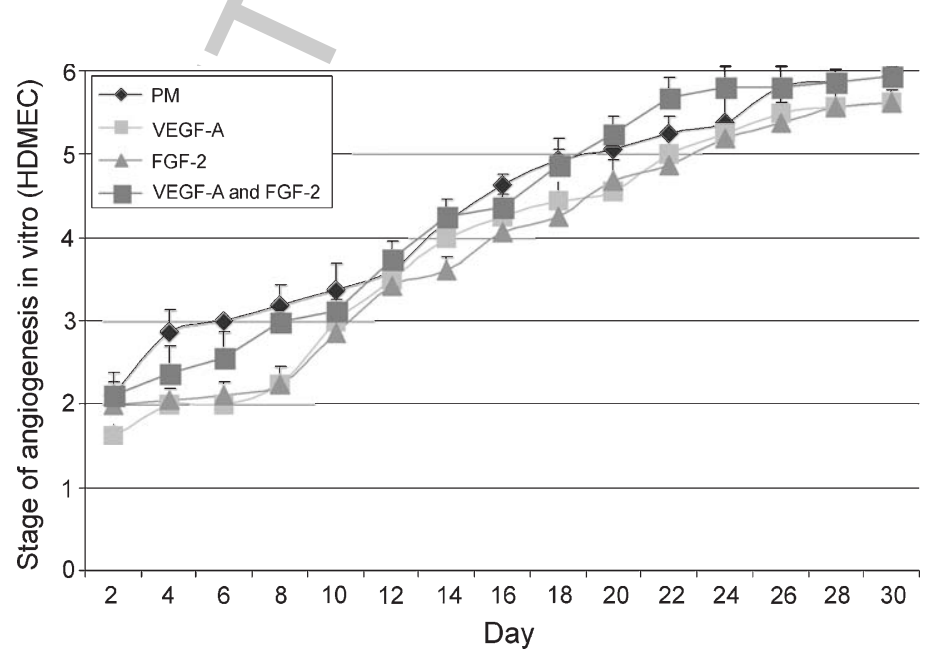

Fig. 4. Stages of angiogenesis in vitro of human dermal microvascular endothelial cells (HDMEC) cultivated in a positive medium (PM), a basal medium supplemented with either FGF-2, or VEGF-A or with both VEGF-A and FGF-2 recorded for 4 visual fields in 4 wells per culture during 30 days, every second day. Mean values per culture with SD are presented. The stages of angiogenesis in vitro of cells incubated in PM differed to cells incubated in VEGF-A, FGF-2, VEGF-A and FGF-2 on day 4 and 6. The stages of angiogenesis in vitro of cells incubated in VEGF-A and FGF-2 differed to cells incubated in VEGF-A or FGF-2 from day 4 to 8 . 


\subsection{Quantitation of angiogenesis in vitro induced by VEGF-A and FGF-2}

The cells incubated in BM remained in stage 1 of angiogenesis in vitro throughout the study. As a consequence these served as negative control, and were omitted from the statistical analysis.

Incubation of endothelial cells in PM led to a chronological run through all stages of angiogenesis. Therefore, endothelial cells incubated in PM served as positive control and the sum of assigned stages of angiogenesis in these cultures $\left(\overline{S_{j}^{\mathrm{PM}}}\right)$ was used for evaluation of the angiogenic potential of the cultures incubated in VEGF-A, FGF-2 or VEGF-A and FGF-2.

The sum of assigned stages of angiogenesis obtained by the HCMEC cultivated in the presence of VEGF-A was $\overline{S_{j}^{\mathrm{VEGF}-\mathrm{A}}}=66.2$, higher than for PM $\left(\overline{S_{j}^{\mathrm{PM}}}=53.8\right)$ and for FGF-2, where it reached $\overline{S_{j}^{\mathrm{FGF}-2}}=59.6(p<0.001)$. The incubation in the presence of both factors resulted in $\overline{S_{j}^{\mathrm{VEGF}-\mathrm{A}+\mathrm{FGF}-2}}=$ 68.1, higher than for PM and FGF-2 $(p<0.001)$. In HCMEC the sum of assigned stages in cultures incubated in BM supplemented with VEGF-A, FGF-2 or both factors was in any case higher than in cultures incubated in PM (Table 3).

The sum of stages of angiogenesis obtained by HDMEC cultivated in the presence of either VEGF-A or FGF-2 was $\overline{S_{j}^{\mathrm{VEGF}-\mathrm{A}}}=58.6$ and $\overline{S_{j}^{\mathrm{FGF}-2}}=57.9$, lower than for PM $\left(\overline{S_{j}^{\mathrm{PM}}}=65.3\right)$ and for the cultures incubated in the presence of both factors, which amount to $\overline{S_{j}^{\mathrm{VEGF}-\mathrm{A}+\mathrm{FGF}-2}}=64.8(p<0.001)$. The sum of assigned stages was equal for VEGF-A and FGF-2, respectively for PM and VEGF-A and FGF-2. In HDMEC the sum of stages of angiogenesis was lower (or almost similar) when cultured in VEGF-A, FGF-2 or both factors compared to cells cultured in PM (Table 3).

Comparing the sum of assigned stages for HCMEC and HDMEC cultured in the same medium, $\overline{S_{j}^{\mathrm{PM}}}$ was lower in HCMEC than in HDMEC $(p<0.001)$, while $\overline{S_{j}^{\mathrm{VEGF}-\mathrm{A}}}(p<0.001)$ and $\overline{S_{j}^{\mathrm{VEGF}-\mathrm{A}+\mathrm{FGF}-2}}(p<0.05)$ were higher in HCMEC than in HDMEC. $\overline{S_{j}^{\mathrm{FGF}-2}}$ was equal for HCMEC and HDMEC (Table 3$)$.

Table 3

Sums of assigned stages of angiogenesis $(S)$ evaluated in in vitro cultures of human heart (HCMEC) and dermal microvascular endothelial cells (HDMEC) in positive medium (PM) or in a basic medium supplemented with either VEGF-A or FGF-2, or both VEGF-A and FGF-2. Four visual fields per well were evaluated and mean values per well together with a mean for each group are presented. Mean values marked with different letters differ significantly $(p<0.05)$ : $\mathrm{a}, \mathrm{b}-$ differences between cell types cultured in the same medium. A, B, C-differences between medium within one cell type. $\mathrm{n}$ - number of visual fields

\begin{tabular}{lccccc}
\hline Cell type & Well & $S^{\text {PM }}$ & $S^{\text {VEGF-A }}$ & $S^{\text {FGF-2 }}$ & $S^{\text {VEGF-A and FGF- }}$ \\
\hline HCMEC & $1(n=4)$ & 55 & 66 & 59 & 67 \\
& $2(n=4)$ & 53 & 65 & 60 & 69 \\
& $3(n=4)$ & 55 & 66 & 58 & 69 \\
& $4(n=4)$ & 53 & 69 & 62 & 68 \\
HDMEC & Mean $(n=16)$ & $53.8 \pm 2.26^{\mathrm{aA}}$ & $66.2 \pm 2.37^{\mathrm{aB}}$ & $59.6 \pm 2.06^{\mathrm{C}}$ & $68.1 \pm 2.70^{\mathrm{aB}}$ \\
& $1(n=4)$ & 66 & 57 & 57 & 63 \\
& $2(n=4)$ & 65 & 58 & 60 & 65 \\
& $3(n=4)$ & 65 & 60 & 56 & 65 \\
& $4(n=4)$ & 65 & 59 & 59 & 66 \\
& Mean $(n=16)$ & $65.3 \pm 3.24^{\mathrm{bA}}$ & $58.6 \pm 3.10^{\mathrm{bB}}$ & $57.9 \pm 3.99^{\mathrm{B}}$ & $64.8 \pm 3.66^{\mathrm{bA}}$ \\
\hline
\end{tabular}




\subsection{Quantitation of gene expression of VEGF-A and FGF-2 receptors VEGFR-1, VEGFR-2 and FGFR-1}

For evaluating the effects of VEGF-A and FGF-2 on angiogenesis in vitro, the gene expression of their endothelial specific receptors VEGFR-1, VEGFR-2 and FGFR-1 was measured at different time points, i.e. day 3, 10, 20 and 40 of cultivation. Regarding the course of expression of each receptor, in both cultures the concentration of VEGFR-1 was higher at day 3 than at day 40. VEGFR-1 showed an intermittent increase from day 3 to day 10 in $\operatorname{HDMEC}$ (Fig. 5). The ratio of VEGFR-2 was approximately constant at the different times of investigation in both cultures with minor variability at day 10 and 20 (Fig. 5). The concentration of FGFR-1 increased from day 3 to day 40; in HCMEC the highest value was measured at day 20, whereas in HDMEC the concentration of FGFR-1 increased continuously over the study (Fig. 5).

Considering the mean amount at all points of investigation (Fig. 6), VEGFR-1 was significantly down-regulated in HCMEC compared to HDMEC $(p<0.001)$, whereas the concentration of VEGFR-2 or FGFR-1 showed no differences between HCMEC and HDMEC. Comparison of the ratio of the both VEGF-receptors within each culture demonstrated that VEGFR-1 was significantly higher than VEGFR-2 in HDMEC $(p<0.001)$. In contrast, VEGFR-1 was significantly lower than VEGFR-2 in $\operatorname{HCMEC}(p<0.05)$.

\section{Discussion}

Until now, no validated in vitro cell culture system exists in the field of angiogenesis research for preclinical investigation and quantitation of the effects of potentially pro- or antiangiogenic factors. Moreover, all available in vitro assays are restricted in mutual comparability as they focus on only one phase of the angiogenic cascade, i.e. migration, proliferation or tube formation $[2,5]$. Therefore, we established an all-in-one assay for quantitation of angiogenesis and antiangiogenesis in vitro that is based on staging of the angiogenic cascade [3,4]. In the present study this assay was used to investigate and quantitate

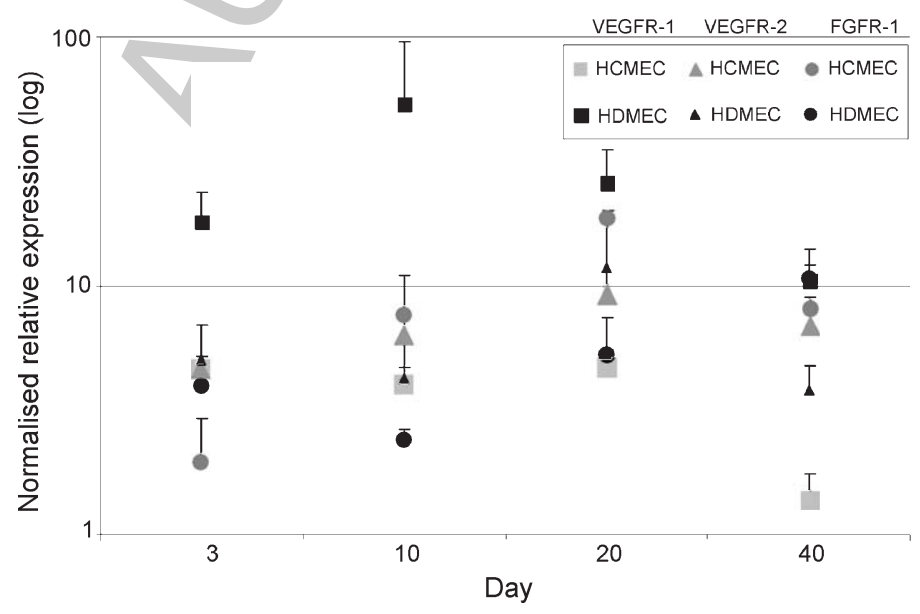

Fig. 5. Gene expression of VEGFR-1, VEGFR-2 and FGFR-1 in human cardiac (HCMEC) and dermal microvascular endothelial cells (HDMEC) after 3, 10, 20 or 40 days of cultivation. Except for day 40 VEGFR-1 in HDMEC was higher expressed than VEGFR-1 in HCMEC. Additionally, except for day 40 VEGFR-1 in HDMEC was higher expressed than VEGFR-2 and FGFR-1 in both HDMEC and HCMEC. 


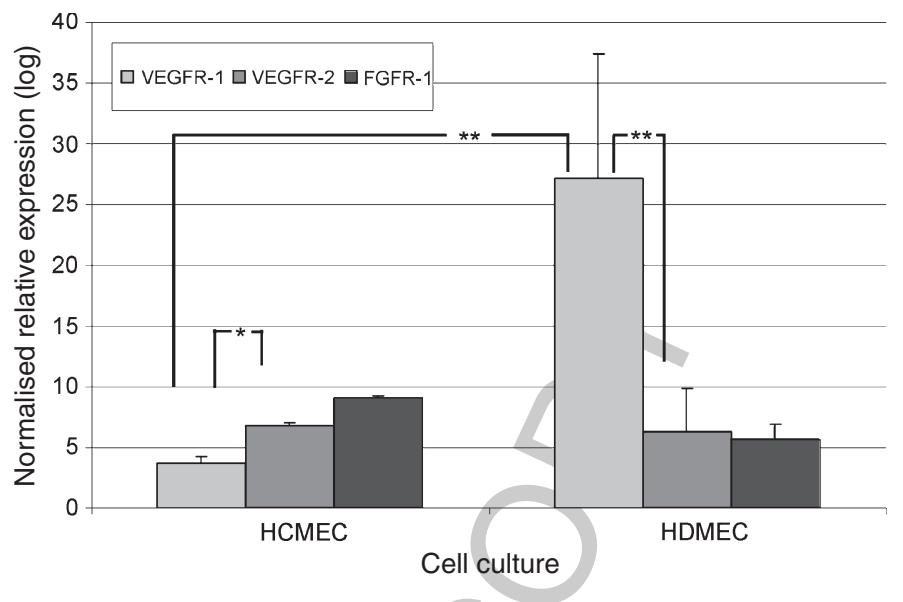

Fig. 6. Gene expression of VEGFR-1, VEGFR-2 and FGFR-1 in human cardiac (HCMEC) and dermal microvascular endothelial cells (HDMEC). In HDMEC VEGFR-1 was expressed significantly higher than VEGFR-2 as well as VEGFR-1 and VEGFR-2 in HCMEC $(p<0.001)$. In HCMEC VEGFR-2 was expressed significantly higher than VEGFR-1 $(p<0.05)$. FGFR-1 was expressed not significantly higher in HCMEC than in HDMEC.

angiogenesis in vitro induced by VEGF-A and FGF-2 in two different human microvascular endothelial cell cultures, derived from the heart (HCMEC) and the skin (HDMEC). For this purpose, VEGF-A and FGF-2 were either applied separately or in combination to both cultures. Additionally, gene expression of their blood vessel endothelial specific receptors, i.e. VEGFR-1, VEGFR-2 and FGFR-1, was quantitated for interpretation and evaluation of the observed effects of the factors on angiogenesis in vitro.

Application of the growth medium provided by the distributor, which was used as positive medium (PM), as wells as VEGF-A, FGF-2 or their combination led both cultures to run through the defined stages of angiogenesis in vitro. This means, that cells of both showed chronologically morphological alterations including elongation, linear arrangement, networking and development of capillary-like structures, which were taken as the basis for the staging of the angiogenic cascade in vitro. However, one difference was found in morphology of developing capillary-like structures, which was subjected to the growth factor used. Incubation of both endothelial cell cultures in VEGF-A led to the development of irregular globular structures alternating with very thin strand-like structures in stage 5 and 6 . This phenomenon could also be observed in vivo during neonatal development of coronary capillaries in mice lacking $\beta 3$-integrin, which modulates VEGF-A induced angiogenesis during the remodelling phase leading to vessel maturation [41]. Due to the successional overshoot of VEGF-A coronary capillaries failed to mature and continued to exhibit irregular endothelial thickness [41]. Furthermore, the development of large, irregular and tortuous vessels in tumours is known to be implicated in high expression levels of VEGF-A [15, 29]. These effects can be explained by the dual role of VEGF-A, acting as an angiogenic but also as a vascular permeability factor $[18,19]$.

Not least, this is the reason why application of VEGF-A alone emerged to be insufficient in angiogenesis therapy [44]. VEGF-A mediates these effects mainly by its receptor VEGFR-2 [17, 32], which was expressed similarly in HCMEC and HDMEC. Therefore, the development of irregular structures could be observed in both endothelial cell cultures treated with VEGF-A alone. In opposite, in cultures incubated either with VEGF-A in combination with FGF-2 or only with FGF-2 regular strand-like structures with diameters up to $30 \mu \mathrm{m}$ developed in stage 5-6. FGF-2 is stated to be an equally potent stimulator of angiogenesis as VEGF-A [7]. However, the results of the present study show that there might be a difference in the quality of the angiogenic effects. A comparative study on the effect of FGF-2 on tumour 
growth and angiogenesis in vivo revealed that high expression levels of FGF-2 in the absence of VEGF-A led to highly vascularised tumours with regular, mature and impermeable vessels [19]. This could be explained by the fact that FGF-2 lacks an effect on vascular permeability [9, 19].

Quantitation of angiogenesis in vitro induced by VEGF-A and FGF-2 in HCMEC and HDMEC showed differences in velocity of the course of stages of angiogenesis depending on the growth factor as well as on the endothelial cell culture used. The slowest run of angiogenesis was observed in HCMEC cultured in PM. However, this culture showed the fastest run of angiogenesis in the presence of VEGF-A alone as well as in the presence of VEGF-A in combination with FGF-2. Incubation of HDMEC with VEGF-A alone resulted in a slower run of angiogenesis in comparison to PM. In addition, the combination of both growth factors provoked a similar pace of angiogenesis as compared to incubation in PM. Summing up these findings, it is obvious that application of VEGF-A accelerated angiogenesis in HCMEC, but not in HDMEC. Considering the expression level of the receptors VEGFR-1 and VEGFR-2, HCMEC showed a significant lower expression of VEGFR-1 than HDMEC, while the concentration of VEGFR-2 was similar in both cultures. Thus, in HCMEC the expression of VEGFR-1 was significant lower than the expression of VEGFR-2. These observation allows the conclusion that low expression levels of VEGFR-1 result in an increase of angiogenic effects of VEGF-A, whereas a high VEGFR-1/VEGFR-2 ratio decelerates angiogenesis in vitro induced by VEGF-A. This phenomenon can be explained by the angiogenic signalling pathways of VEGFR-1 and VEGFR-2: It is known, that activation of VEGFR-1 inhibits the proangiogenic effects of VEGF-A via VEGFR-2 by sequestering this factor and thus making it less available to VEGFR-2 [12]. Therefore, VEGFR-1 is suggested to function primarily as a decoy receptor or as a non-signalling 'reservoir' for VEGF-A. Displacing VEGF-A from VEGFR-1 provides additional VEGF-A available to induce VEGFR-2-mediated angiogenic signalling [27]. The proangiogenic effects of VEGF-A are essentially provoked by activation of VEGFR-2, which induces the initial steps of angiogenesis, i.e. migration and proliferation of vascular endothelial cells [7, 32, 37, 38].

Application of FGF-2 showed in both cultures a similar run of angiogenesis. This observation was as expected, because FGFR-1 was expressed equally in both endothelial cell cultures. However, in comparison to cultures incubated in PM, FGF-2 yielded acceleration of angiogenesis in HCMEC and deceleration of angiogenesis in HDMEC. This might be assigned to the distinct velocity of angiogenesis influenced by PM in the different cultures. This will be investigated in a further study on analysis of the other growth factors containing in PM, which was named by the distributor, as well as their corresponding receptors.

In conclusion, the established all-in-one angiogenesis assay was used successfully for quantitation of angiogenesis in vitro induced by VEGF-A and FGF-2, and the proangiogenic effects of these growth factors were confirmed. It was further demonstrated that application of VEGF-A alone resulted in incomplete and aberrant angiogenesis. In addition, the expression of the distinct receptors VEGFR-1 and VEGFR-2 seemed to provoke quantitative effects of VEGF-A on angiogenesis in vitro. Thus, it becomes apparent that statements on qualitative effects of VEGF-A or FGF-2 on angiogenesis in vitro are comparable in the different endothelial cultures used. However, quantitative effects are particularly affected by the corresponding receptors, and therefore, cannot be extrapolated from one to another endothelial cell culture.

\section{Acknowledgements}

The authors wish to acknowledge the Ministery of Environment, Forestry and Consumer Protection of Rheinland-Pfalz and the research foundation - Flanders (FWO) for financial support and Ms. Angelika Mai for excellent technical assistance. 


\section{References}

[1] I.R. Asplin, S.M. Wu, S. Mathew, G. Bhattachariee and S.V. Pizzo, Differential regulation of the fibroblast growth factor (FGF) family by alpha(2)-macroglobulin: Evidence for selective modulation of FGF-2-induced angiogenesis, Blood $\mathbf{9 7}$ (2001), 3450-3457.

[2] R. Auerbach, R. Lewis, B. Shinners, L. Kubai and N. Akhtar, Angiogenesis assays: A critical overview, Clin Chem 49 (2003), 32-40.

[3] M. Bahramsoltani and J. Plendl, A new in vitro model to quantify angiogenesis, ALTEX 21 (2004), 227-244.

[4] M. Bahramsoltani and J. Plendl, Different ways to antiangiogenesis by angiostatin and suramin, and quantitation of angiostatin-induced antiangiogenesis, APMIS 115 (2007), 30-46.

[5] M. Bahramsoltani, J. Plendl, P. Janczyk, P. Custodis and S. Kaessmeyer, Quantitation of angiogenesis and antiangiogenesis in vivo, ex vivo and in vitro - an overview, ALTEX 26 (2009), 95-107.

[6] D. Baudry, M. Faussillon, M.-O. Cabanis, M. Rigolet, J.-M. Zucker, C. Patte, S. Sarnacki, L. Boccon-Gibod, C. Junien and C. Jeanpierre, Changes in WT1 splicing are associated with a specific gene expression profile in Wilms' tumour, Oncogene 21 (2002), 5566-5573.

[7] S.V. Bhadada, B.R. Goval and M.M. Patel, Angiogenic targets for potential disorders, Fundam Clin Pharmacol (2010), Epub ahead of print.

[8] C. Borselli, O. Oliviero, S. Battista, L. Ambrosio and P.A. Netti, Induction of directional sprouting angiogenesis by matrix gradients, J Biomed Mager Res A 80 (2007), 297-305.

[9] R. Cao, E. Brakenhielm, R. Pawliuk, D. Wariaro, M.J. Post, E. Wahlberg, P. Leboulch and Y. Cao, Angiogenic synergism, vascular stability and improvement of hind-limb ischemia by a combination of PDGF-BB and FGF-2, Nat Med 9 (2003), 604-613.

[10] Y. Cao, Monotherapy versus combination therapy of angiogenic and arteriogenic factors for the treatment of ischemic disorders, Curr Mol Med 9 (2009), 967-972.

[11] P. Carmeliet, Angiogenesis in health and disease, Nat Med 9 (2003), 653-660.

[12] P. Carmeliet, L. Moons, A. Luttun, V. Vincenti, V. Compernolle, M. De Mol, Y. Wu, F. Bono, L. Devy, H. Beck, D. Scholz, T. Acker, T. DiPalma, M. Dewerchin, A. Noel, I. Stalmans, A. Barra, S. Blacher, T. Vandendriessche, A. Ponten, U. Eriksson, K.H. Plate, J.M. Foidart, W. Schaper, D.S. Charnock-Jones, D.J. Hicklin, J.M. Herbert, D. Collen and M.G. Persico, Synergism between vascular endothelial growth factor and placental growth factor contributes to angiogenesis and plasma extravasation in pathological conditions, Nat Med 7 (2001), 575-583.

[13] U. Cavallaro, M. Tenan, V. Castelli, A. Perilli, N. Maggiano, E.G. Van Meir, R. Montesano, M.R. Soria and M.S. Pepper, Response of bovine endothelial cells to FGF-2 and VEGF is dependent on their site of origin: Relevance to the regulation of angiogenesis, J Cell Biochem 82 (2001), 619-633.

[14] A. Dallol, N. Da Silva, P. Viacava, J. Minna, I. Bieche, E. Maher and F. Latif, SL1T2, a human homologue of the Drosophila Slit2 gene, has tumor suppressor activity and is frequently inactivated in lung and breast cancers, Cancer Res 62 (2002), 5874-5880.

[15] U. Eriksson and K. Alitalo, VEGF receptor 1 stimulates stem-cell recruitment and new hope for angiogenesis therapies, Nat Med 8 (2002), 775-777.

[16] N. Ferrara, Role of vascular endothelial growth factor in physiologic and pathologic angiogenesis: Therapeutic implications, Semin Oncol 29 (2002), 10-14.

[17] N. Ferrara, H.P. Gerber and J. LeCouter, The biology of VEGF and its receptors. Nat Med 9 (2003), 669-676.

[18] R.P. Franke, R. Fuhrmann, B. Hiebl, C. Mrowietz and F. Jung, Permeability of technical and biological tissues, Clin Hemorheol Microcirc 43(1) (2009), 149-155.

[19] R. Giavazzi, B. Sennino, D. Coltrini, A. Garofalo, R. Dossi, R. Ronca, M.P. Tosatti and M. Presta, Distinct role of fibroblast growth factor-2 and vascular endothelial growth factor on tumor growth and angiogenesis, Am J Pathol 162 (2003), 1913-1926.

[20] A.W. Griffioen and G. Molema, Angiogenesis: Potentials for pharmacologic intervention in the treatment of cancer, cardiovascular diseases, and chronic inflammation, Pharmacol Rev 52 (2000), 237-268.

[21] F.S. Grünewald, A.E. Prota, A. Giese and K. Ballmer-Hofer, Structure-function analysis of VEGF receptor activation and the role of coreceptors in angiogenic signalling, Biochim Biophys Acta 1804 (2010), 567-580.

[22] J. Hellemans, G. Mortier, A. De Paepe, F. Speleman and J. Vandesompele, qBase relative quantification framework and software for management and automated analysis of real-time quantitative PCR data, Genome Biol 8 (2007), R19. 
[23] R.K. Jain, Molecular regulation of vessel maturation, Nat Med 9 (2003), 685-693.

[24] L. Jingjing, Y. Xue, N. Agarwal and R.S. Roque, Human Müller cells express VEGF183, a novel spliced variant of vascular endothelial growth factor, Invest Ophthalmol Vis Sci 40 (1999), 752-759.

[25] T. Lange, N. Guttmann-Raviv, L. Baruch, M. Machluf and G. Neufeld, VEGF162, a new heparin-binding vascular endothelial growth factor splice form that is expressed in transformed human cells, J Biol Chem 278 (2003), 17164-17169.

[26] S. Lefever, J. Vandesompele, F. Speleman and F. Pattyn, RTPrimerDB: The portal for real-time PCR primers and probes, Nucleic Acids Res 37 (2009), D942-D945.

[27] A. Luttun, M. Tjwa, L. Moons, Y. Wu, A. Angelillo-Scherrer, F. Liao, J.A. Nagy, A. Hooper, J. Priller, B. De Klerck, V. Compernolle, E. Daci, P. Bohlen, M. Dewerchin, J.M. Herbert, R. Fava, P. Matthys, G. Carmeliet, D. Collen, H.F. Dvorak, D.J. Hicklin and P. Carmeliet, Revascularization of ischemic tissues by PlGF treatment, and inhibition of tumor angiogenesis, arthritis and atherosclerosis by anti-Flt1, Nat Med $\mathbf{8}$ (2002), 831-840.

[28] R.M. Murphy, K.K. Watt, D. Cameron-Smith, C.J. Gibbons and R.J. Snow, Effects of creatine supplementation on housekeeping genes in human skeletal muscle using real-time RT-PCR, Physiol Genomics 12 (2003), 163-174.

[29] J.A. Nagy, S.H. Chang, A.M. Dvorak and H.F. Dvorak, Why are tumour blood vessels abnormal and why is it important to know? Br J Cancer 100 (2009), 865-869.

[30] G. Neufeld, T. Cohen, S. Gengrinovitch and Z. Poltorak, Vascular endothelial growth factor (VEGF) and its receptors, FASEB J 13 (1999), 9-22.

[31] M.W. Pfaffl, G.W. Horgan and L. Dempfle, Relative expression software tool (REST) for group-wise comparison and statistical analysis of relative expression results in real-time PCR, Nucleic Acids Res 30 (2002), e36.

[32] D. Ribatti, M.T. Conconi and G.G. Nussdorfer, Nonclassic endogenous novel regulators of angiogenesis, Pharmacol Rev 59 (2007), 185-205.

[33] D. Ribatti and M. Presta, The role of fibroblast growth factor-2 in the vascularization of the chick embryo chorioallantoic membrane, J Cell Mol Med 6 (2002), 439-446.

[34] S. Steckelbroeck, M. Watzka, D. Ltjohann, P. Makiola, A. Nassen, V.H. Hans, H. Clusmann, A. Reissinger, M. Ludwig, L. Siekmann and D. Klingmller, Characterization of the dehydroepiandrosterone (DHEA) metabolism via oxysterol 7alphahydroxylase and 17-ketosteroid reductase activity in the human brain, J Neurochem 83 (2002), 713-726.

[35] L.K. Sussman, J.N. Upalakalin, M.J. Roberts, O. Kocher and L.E. Benjamin, Blood markers for or vasculogenesis increase with tumor progression in patients with breast carcinoma, Cancer Biol Ther 2 (2003), 255-256.

[36] G. Szebenyi and J.F. Fallon, Fibroblast growth factors as multifunctional signaling factors, Int Rev Cytol 185 (1999), 45-106.

[37] T. Takahashi, S. Yamaguchi, K. Chida and M. Shibuya, A single autophosphorylation site on KDR/Flk-1 is essential for VEGF-A-dependent activation of PLC-gamma and DNA synthesis in vascular endothelial cells, EMBO J 20 (2001), 2768-2778.

[38] J. Tran, Z. Master, J.L. Yu, J. Rak, D.J. Dumont and R.S. Kerbel, A role of surviving in chemoresistance of endothelial cells mediated by VEGF, Proc Natl Acad Sci USA 99 (2002), 4349-4354.

[39] N. Turner and R. Grose, Fibroblast growth factor signalling: From development to cancer, Nat Rev Cancer 10 (2010), $116-129$.

[40] J. Vandesompele, K. De Preter, F. Pattyn, B. Poppe, N. Van Roy, A. De Paepe and F. Speleman, Accurate normalization of real-time quantitative RT-PCR data by geometric averaging of multiple internal control genes, Genome Biol 3 (2002), RESEARCH0034.

[41] S.M. Weis, J.N. Lindquist, L.A. Barnes, K.M. Lutu-Fuga, J. Cui, M.R. Wood and D.A. Cheresh, Cooperation between VEGF and beta3 integrin during cardiac vascular development, Blood 109 (2007), 1962-1970.

[42] G.D. Yancopoulos, S. Davis, N.W. Gale, J.S. Rudge, S.J. Wiegand and J. Holash, Vascular-specific growth factors and blood vessel formation, Nature 407 (2000), 242-248.

[43] M. Ziche, S. Donnini and L. Morbidelli, Development of new drugs in angiogenesis, Curr Drug Targets 5 (2004), 485-493.

[44] B. Zhou, M.C. Poon, W.T. Pu and Z.C. Han, Therapeutic neovascularization for peripheral arterial diseases: Advances and perspectives, Histol Histopathol 22 (2007), 667-686. 